\title{
EU-TIRADS-Based Omission of Fine-Needle Aspiration and Cytology from Thyroid Nodules Overlooks a Substantial Number of Follicular Thyroid Cancers
}

\author{
Tamas Solymosi ${ }^{D},{ }^{1}$ Laszlo Hegedüs, ${ }^{2}$ Miklos Bodor, ${ }^{3}$ and Endre V. Nagy ${ }^{3}{ }^{3}$ \\ ${ }^{1}$ Endocrinology and Metabolism Clinic, Bugat Hospital, 20 Dozsa u, H-3200 Gyöngyös, Hungary \\ ${ }^{2}$ Department of Endocrinology, Kløvervonget 6, 5.sal, Odense University Hospital, DK-5000 Odense, Denmark \\ ${ }^{3}$ Division of Endocrinology, Department of Medicine, Faculty of Medicine, University of Debrecen, 98 Nagyerdei krt, \\ H-4032 Debrecen, Hungary
}

Correspondence should be addressed to Tamas Solymosi; solymosi@thyrosite.com

Received 27 March 2021; Revised 4 August 2021; Accepted 2 September 2021; Published 27 September 2021

Academic Editor: Thomas J. Fahey

Copyright (c) 2021 Tamas Solymosi et al. This is an open access article distributed under the Creative Commons Attribution License, which permits unrestricted use, distribution, and reproduction in any medium, provided the original work is properly cited.

\begin{abstract}
Background. The classification of nodules by Thyroid Imaging Reporting and Data Systems (TIRADS) is important in guiding management. Whether sensitivity in identifying thyroid cancers varies with thyroid cancer phenotype remains unclarified. Methods. The ultrasound (US) characteristics of nodules of 26,908 nodular goiter patients were recorded. Fine-needle aspiration cytology (FNA) was performed in all nodules $>1 \mathrm{~cm}$ irrespective of US findings $(n=25,025)$ and in nodules between $5 \mathrm{~mm}$ and $10 \mathrm{~mm}$ with suspicious US characteristics $(n=1,883)$. Of the 3281 operated cases, 221,30 , and 23 were papillary (PTC), follicular (FTC), and medullary (MTC) cancers, respectively. The US-based indication of FNA, as defined by EU-TIRADS scores, combined with lesion size, was calculated. This study design is unique in avoiding the common selection bias when TIRADS' sensitivity is tested in a cohort selected for FNA and surgery based on the same US characteristics on which TIRADS is based. Results. The EUTIRADS score influences decision of FNA in the $10-20 \mathrm{~mm}$ range. In such nodules $(n=118)$, the number of suspicious features (marked hypoechogenicity, microcalcifications, irregular shape, and irregular border) per lesion was lower in FTC (0.7 \pm 0.6$)$ than in PTC $(1.7 \pm 1.0)$ or MTC $(1.8 \pm 0.7 ; p<0.02)$, resulting in EU-TIRADS scores of $4.1 \pm 0.6,4.8 \pm 0.3$, and $4.9 \pm 0.2$, respectively $(p<0.01)$. The EU-TIRADS-based FNA indication rate was lower in FTC $(55.5 \%)$ compared to PTC (85.0\%) and MTC (88.9\%) $(p=0.02)$. Conclusions. EU-TIRADS-defined suspicious US features are less common in FTC than in PTC and MTC. Therefore, a substantial number of FTCs in the $10-20 \mathrm{~mm}$ range escape surgery.
\end{abstract}

\section{Introduction}

There has been a continuous development over the past 40 years in the selection of thyroid nodules that qualify for fineneedle aspiration cytology (FNA). The main initial driver is used for recognizing all malignancies; the principle of reaching the highest sensitivity was supported by the introduction of thyroid ultrasound (US) in everyday practice. From the pre-US era, when FNA was indicated in palpable "cold" thyroid nodules [1], the number of biopsies gradually rose and peaked around the publication of the AACE/ACE guideline in 2006 (AACE-2006). This guideline suggested
FNA of all nodules larger than $10 \mathrm{~mm}$ and even of smaller ones presenting clinical or US suspicion of cancer [2].

In the past 10 years, focus has changed and has mainly been driven by the principle of balancing diagnostic sensitivity and specificity and reducing the number of FNAs. The main tool for this change has been the consideration of suspicious ultrasound characteristics for the decision of performing FNA [3-11]. Practically, all guidelines published since 2006 link indications for cytology to suspicious US signs. There are some differences between various thyroid nodule image reporting and data systems (TIRADS) [5-9] in what is considered suspicious and in the smallest thyroid 
nodule size worth considering for cytology. Using the same approach, the various TIRADS have clarified which ultrasound patterns merit cytology; furthermore, sampling is not recommended for isoechoic nodules between $1 \mathrm{~cm}$ and $2 \mathrm{~cm}$ in diameter and for those between $1 \mathrm{~cm}$ and $1.5 \mathrm{~cm}$ that do not show suspicious signs, as stated by the AACE-TIRADS, ACR-TIRADS, EU-TIRADS $[5,6,8]$, and ATA-TIRADS and KSTR-TIRADS [7, 9], respectively.

The bases of all TIRADS systems are those US characteristics which have diagnostic importance in the recognition of papillary thyroid carcinomas (PTC) [12]. The US characteristics of FTC differ profoundly from PTC characteristics [13-15]. Only a limited number of studies deal with the importance of TIRADS in medullary thyroid cancer (MTC) [16-20] and follicular thyroid cancer (FTC) [21-23]. To the best of our knowledge, there has been only one study which focuses on the diagnostic performance of TIRADS in patient selection for FNA in FTC [23]. The fact that TIRADS' performance has been tested almost exclusively in PTC patients supports the view that the clinical validity of TIRADS systems cannot be unconditionally extended to other forms of thyroid malignancy [24]. Therefore, while the US-centered diagnostic work-up can effectively identify PTCs, it is not known if TIRADS systems are similarly successful in finding FTCs and MTCs burdened by substantially higher risk of mortality [25-27].

In the present study, the effectiveness of EU-TIRADSbased nodule selection in the detection of FTC and MTC was retrospectively analyzed in a patient cohort which underwent FNA irrespective of the EU-TIRADS-based criteria for suspicion.

1.1. Patients and Methods. Between January 2006 and December 2018, 26908 patients, evaluated at the Thyroid Clinic of the Bugat Pal Hospital (Gyöngyös, Hungary), were diagnosed with thyroid nodules. In all patients, US was performed and TSH was measured, supplemented with FT4 and FT3 if needed. The decision of FNA was made in accordance with the AACE-2006 guideline [2], i.e., US-guided FNA was performed in patients with nontoxic nodules larger than $10 \mathrm{~mm}$ in maximal diameter. The same protocol was followed throughout the 13 years, i.e., no alteration was made after the publication of the AACE/ACE/AME 2016 guidelines [5]. If the clinical examination, patient history, or US signs suggested increased risk of thyroid cancer, hypoechogenic nodules between $5 \mathrm{~mm}$ and $10 \mathrm{~mm}$ were also aspirated. FNA was also performed if the only suspicious sign was the presence of pathological cervical lymph nodes by US. For nonoperated patients, follow-up US was performed after 1-3 years, and FNA repeated if the nodule volume grew by more than $33 \%$. US and cytology were performed by the same examiner (TS) with 22 years of experience in this field. In the first 6 years of the study, a SonoSite Micromaxx (Bothell, WA, USA) with a $5-10 \mathrm{MHz}$ probe was used, while in the subsequent years, a Philips CX50 ultrasound machine (Eindhoven, the Netherlands) with a $5-12 \mathrm{~Hz}$ transducer was used for US of the thyroid and the neck.
The following standard US features of the nodules were recorded and analyzed: the three diameters, composition, echogenicity, presence of microcalcifications, taller-thanwide shape, and macrocalcifications (including peripheral eggshell calcification). Composition was classified as solid (solid portion $\geq 90 \%$ ), predominantly solid (solid portion $50-90 \%$ ), predominantly cystic (solid portion $<50 \%$ ), and cystic (solid portion $<10 \%$ ). The nodule was classified as hyperechoic, isoechoic, or hypoechoic compared to the surrounding nonnodular thyroid tissue. Hypoechoic nodules were subdivided as minimally/moderately hypoechogenic or markedly hypoechogenic, i.e., less or more hypoechoic as compared to the adjacent cervical muscles, respectively. Margins were classified as regular or irregular (lobulated or spiculated).

Altogether, 3281 patients were operated on. The indications for surgery were (i) suspicious cytology (Table 1), (ii) benign or repeatedly nondiagnostic cytology combined with clinical and/or US suspicion of malignancy, (iii) compression signs and/or symptoms, or (iv) patient preference. TNM and clinical staging were according to the most recent classification [28].

Based on final histology, 338 patients had thyroid cancer. After exclusion of patients with cancers other than PTC, FTC, or MTC, those who had previous thyroid surgery, and the 5 papillary cancers (because it was equivocal which of the nodules were malignant), 274 nodules remained and were retrospectively analyzed. Of these 274 nodules, 221 were PTC, 30 FTC, and 23 MTC. In multifocal carcinomas, only one focus (the largest one) was included in the analysis. The most important clinical data of the patients and the results of FNA at the first examination are summarized in Table 1.

EU-TIRADS scores were retrospectively generated in all 274 cases. The score for a given nodule was translated into "for" or "against" the subsequent use of FNA [8]. FNA was considered indicated even if it was substantiated merely by the presence of pathological lymph nodes.

The EU-TIRADS score, based on US characteristics other than the maximal diameter of the nodule, influences the decision of FNA in lesions between $10 \mathrm{~mm}$ and $20 \mathrm{~mm}$ in maximal diameter. Nodules with their largest diameter in this range, and proven to be PTC, FTC, or MTC by final histology, were retrospectively analyzed regarding the prevalence of suspicious US characteristics: marked hypoechogenicity, taller-than-wide shape, irregular (lobulated or spiculated) margins, and microcalcifications [8].

The retrospective analysis of the data stored in the hospital database has been preapproved by the Ethics Committee of the Bugat Pal Hospital, Gyöngyös, Hungary. For statistical comparisons, Fisher's exact test and the Mann-Whitney $U$ test were used.

\section{Results}

2.1. Size Distribution of the Three Cancer Types. Distribution of cancers according to thyroid nodule size is shown in Figure 1. A larger proportion of PTCs $(63 / 221$; $28.5 \%)$, compared with non-PTCs $(3 / 53 ; 5.8 \%)$, was $\leq 10 \mathrm{~mm}$ 
TAвLE 1: The clinical and histopathological data of the 274 thyroid cancer patients.

\begin{tabular}{|c|c|c|c|}
\hline & Follicular cancer $(N=30)$ & Papillary cancer $(N=221)$ & $\begin{array}{c}\text { Medullary cancer } \\
(N=23)\end{array}$ \\
\hline Male : female & $5: 25$ & $45: 176$ & $5: 18$ \\
\hline Age (years) mean \pm SD & $50.4 \pm 17.1$ & $43.4 \pm 15.0$ & $56.6 \pm 17.0$ \\
\hline Maximum diameter of the tumor $(\mathrm{mm})$, mean \pm SD & $27.2 \pm 12.4$ & $17.3 \pm 9.9$ & $26.2 \pm 17.0$ \\
\hline \multirow{6}{*}{ Results of FNA according to the Bethesda classification ${ }^{1}$} & $1: 1$ & $1: 14$ & 1: 0 \\
\hline & 2: 1 & 2: 8 & 2: 1 \\
\hline & 3: 1 & 3: 1 & 3: 0 \\
\hline & 4: 22 & 4: 13 & 4: 0 \\
\hline & 5: 5 & 5: 68 & 5: 5 \\
\hline & 6: 0 & 6: 117 & 6: 17 \\
\hline \multirow{4}{*}{ Histopathological stage ${ }^{1}$} & Stage I: 11 & Stage I: 139 & Stage I: 7 \\
\hline & Stage II: 11 & Stage II: 46 & Stage II: 6 \\
\hline & Stage III: 3 & Stage III: 28 & Stage III: 6 \\
\hline & Stage IV: 5 & Stage IV: 8 & Stage IV: 4 \\
\hline
\end{tabular}

${ }^{1}$ Histopathological staging according to reference [28].

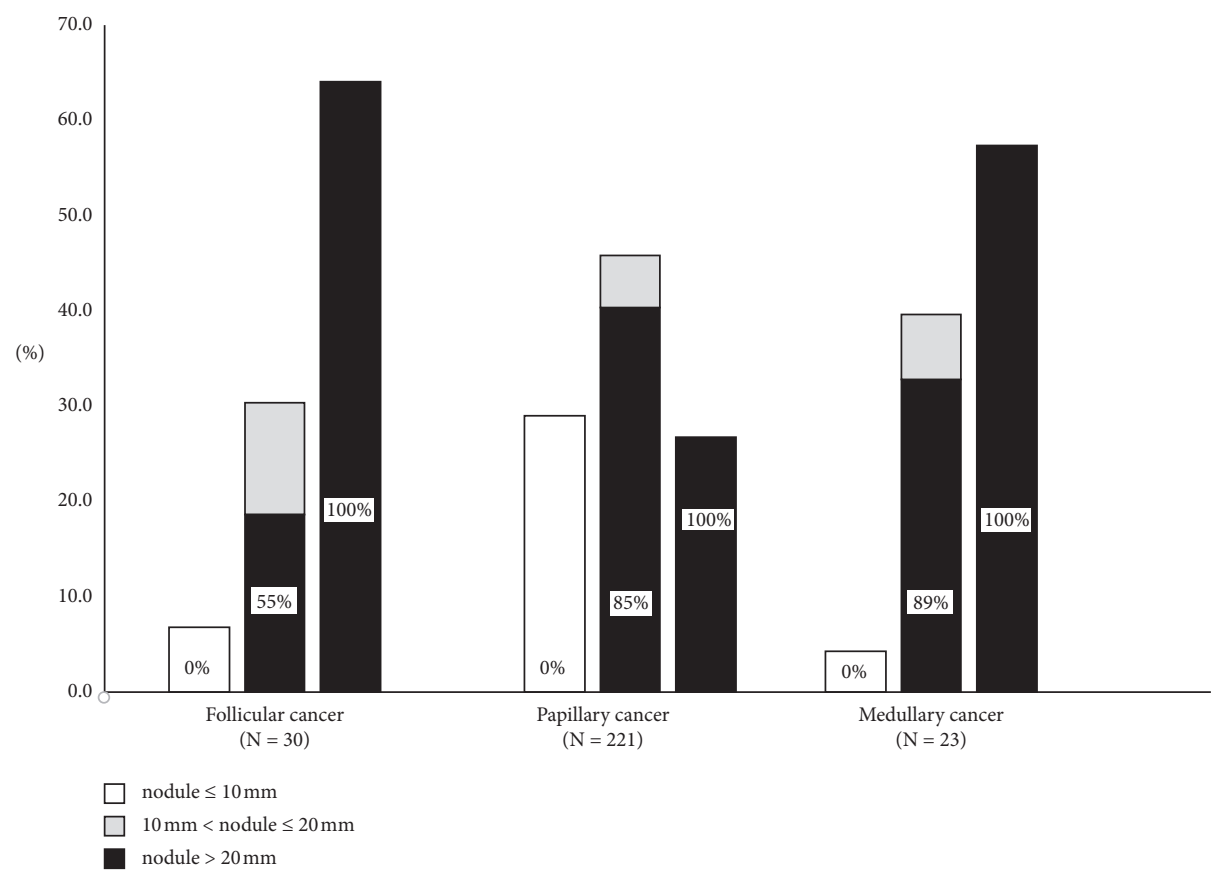

FIGURE 1: Indication of FNA based on EU-TIRADS. Size distribution of the three major thyroid cancer types; shaded areas show the proportion of the nodules in which the EU-TIRADS-based approach would have indicated FNA. The values in the bars are given in \%.

$(p=0.0005)$. These carcinomas would have been lost to diagnosis based solely on EU-TIRADS size criteria (Table 2).

A significantly larger proportion of FTCs $(19 / 30 ; 63.3 \%)$ compared with non-FTCs $(71 / 244 ; 25.9 \%, p=0.0002)$ was $\geq 20 \mathrm{~mm}$. In this size range, EU-TIRADS-based decision of FNA would have identified all cancers (Table 2).

The largest diameter of the nodules was between $10 \mathrm{~mm}$ and $20 \mathrm{~mm}$ in $118 / 274(43.1 \%)$ of the carcinomas. This is the subgroup of patients in which the US characteristics influence the decision regarding FNA. EU-TIRADS would have indicated FNA in $88.9 \%$ of MTCs, $85.0 \%$ of PTCs, and $55.6 \%$ of FTCs, the difference between non-FTC and FTC being significant $(p=0.02)$ (Table 3 ). According to the AACE-2006 guideline, we aspirated all nodules, including follicular cancers, in this size range (Figure 2). However, based on US-driven indication of FNA, $44.4 \%$ of follicular cancers in the $10-20 \mathrm{~mm}$ size range would have escaped detection due to their low EU-TIRADS score (Table 3).

\subsection{The Distribution of Major Ultrasound Characteristics in} the 10-20 $\mathrm{mm}$ Size Range. Further analyses were performed in nodules with largest diameter between $10 \mathrm{~mm}$ and $20 \mathrm{~mm}$ because their US characteristics determine if EU-TIRADS suggests FNA (Table 4). The mean number of the four possible suspicious US features per nodule was lower in FTC $(0.67 \pm 0.59)$ compared to MTC $(1.78 \pm 0.74 ; p=0.01)$ and PTC $(1.68 \pm 0.98 ; p=0.002)$. There was no significant difference between MTC and PTC in this respect $(p=0.77)$. The mean EU-TIRADS score was lower in FTC (4.11 \pm 0.59$)$ 
TABLE 2: Evaluation of nodular goiter based on the 2006 Guideline of the AACE/ACE and on the EU-TIRADS in relation to missing the cancer diagnosis in three subtypes of thyroid cancers.

\begin{tabular}{|c|c|c|c|}
\hline \multirow{2}{*}{ Maximal diameter of the nodule } & \multicolumn{3}{|c|}{ Indication of FNA } \\
\hline & $\leq 10 \mathrm{~mm}$ & $10 \mathrm{~mm}-20 \mathrm{~mm}$ & $>20 \mathrm{~mm}$ \\
\hline AACE/ACE guideline (2006) & $\begin{array}{l}\text { Suspicious } \\
\text { lesion }\end{array}$ & All nodules & All nodules \\
\hline EU-TIRADS (2017) & If equivocal $^{1}$ & $\begin{array}{c}\text { Depending on the EU-TIRADS } \\
\text { score }\end{array}$ & $\begin{array}{c}\text { All } \\
\text { nodules }\end{array}$ \\
\hline $\begin{array}{l}\text { Overlooked carcinomas by EU-TIRADS ( } \% \text { of all cancers of that type } \\
\text { irrespective of nodule size) }\end{array}$ & $\begin{array}{l}6.7 \% \text { of } \mathrm{FTC}^{3} \\
4.3 \% \text { of } \mathrm{MTC}^{3} \\
28.5 \% \text { of } \mathrm{PTC}^{3}\end{array}$ & $\begin{array}{l}13.3 \% \text { of FTC } \\
4.3 \% \text { of MTC } \\
5.2 \% \text { of PTC }\end{array}$ & $\begin{array}{l}\text { None } \\
\text { None } \\
\text { None }\end{array}$ \\
\hline $\begin{array}{l}\text { Overlooked carcinomas by EU-TIRADS (\% of cancers within the specific } \\
\text { size limits) }\end{array}$ & $\begin{array}{l}100 \% \text { of } \mathrm{FTC}^{3} \\
100 \% \text { of } \mathrm{MTC}^{3} \\
100 \% \text { of } \mathrm{PTC}^{3}\end{array}$ & $\begin{array}{l}44.4 \% \text { of FTC } \\
11.1 \% \text { of MTC } \\
15.0 \% \text { of PTC }\end{array}$ & $\begin{array}{l}\text { None } \\
\text { None } \\
\text { None }\end{array}$ \\
\hline & $3.3 \%$ of FTC & $0 \%$ in FTC & $\begin{array}{l}3.3 \% \text { of } \\
\text { FTC }\end{array}$ \\
\hline $\begin{array}{l}\text { Inaccuracy of FNA: nondiagnostic and false-negative results (related to all } \\
\text { cancers of that type) }\end{array}$ & $0 \%$ of MTC & $4.3 \%$ of MTC & $0 \%$ in MTC \\
\hline & $1.8 \%$ of PTC & $3.2 \%$ of PTC & $\begin{array}{l}5.0 \% \text { of } \\
\text { PTC }\end{array}$ \\
\hline
\end{tabular}

EU-TIRADS, Thyroid Imaging Reporting and Data System of the European Thyroid Association [8]; AACE/ACE, American Association of Clinical Endocrinologists (AACE) and American College of Endocrinology (ACE) [2]. ${ }^{1}$ EU-TIRADS suggests "FNA or active surveillance." ${ }^{2}$ Except for pure cysts and entirely spongiform cysts. ${ }^{3}$ Overlooked if FNA would not have been performed in suspicious lesions $\leq 10 \mathrm{~mm}$.

TABLE 3: EU-TIRADS-based indication of FNA. Both the EU-TIRADS score and nodule size influence the indication.

\begin{tabular}{lcccccc}
\hline $\begin{array}{l}\text { Largest } \\
\text { diameter }\end{array}$ & $\begin{array}{c}\text { Follicular cancer }(n=30) \\
\text { Number of } \\
\text { lesions }\end{array}$ & $\begin{array}{c}\text { FNA indicated, } n \\
(\%)\end{array}$ & $\begin{array}{c}\text { Number of } \\
\text { lesions }\end{array}$ & $\begin{array}{c}\text { FNA indicated, } n \\
(\%)\end{array}$ & $\begin{array}{c}\text { Papillary cancer }(n=221) \\
\text { Number of } \\
\text { lesions }\end{array}$ & $\begin{array}{c}\text { FNA indicated }{ }^{1}, n \\
(\%)\end{array}$ \\
\hline$\leq 10 \mathrm{~mm}$ & 2 & $0(0)$ & 1 & $0(0)$ & 63 & $0(0)$ \\
$10-20 \mathrm{~mm}$ & 9 & $5(55.6)$ & 9 & $8(88.9)$ & 100 & $85(85.0)$ \\
$>20 \mathrm{~mm}$ & 19 & $19(100)$ & 13 & $13(100)$ & 58 & $58(100)$ \\
\hline
\end{tabular}

EU-TIRADS, Thyroid Imaging Reporting and Data System of the European Thyroid Association. ${ }^{1}$ According to the suggestions of the EU-TIRADS, FNA was considered indicated even if it was substantiated only on the presence of pathological lymph nodes.

compared with MTC $(4.89 \pm 0.20)$ and PTC $(4.80 \pm 0.33)$ ( $p=0.02$ and $p=0.01$, respectively).

\subsection{The Clinical Stage in Relation to EU-TIRADS-Based FNA} Indication in 10-20 $\mathrm{mm}$ Nodules. There were 4 FTCs, 1 MTC, and 15 PTCs among lesions between $10 \mathrm{~mm}$ and $20 \mathrm{~mm}$ in diameter in which FNA would not have been indicated based on EU-TIRADS alone (Table 5). Two PTC patients presented with a large goiter, which required surgery. Both patients had $\mathrm{T} 1$ and stage I thyroid cancer. In the remaining 18 patients, including the 4 FTCs, FNA was the sole diagnostic test directing the patient towards surgery.

Out of these 20 cases, in which FNA would not have been indicated based merely on EU-TIRADS, four were T4 cancers (1 FTC and 3 PTCs) and two were stage IV carcinomas (1 FTC and 1 PTC) in which lung and bone metastases were revealed by postradioiodine therapy SPECTCT.

\section{Discussion}

Since 2017, EU-TIRADS has been widely used for selection of thyroid nodules for FNA. The EU-TIRADS scores influence the decision of FNA in lesions with a maximum diameter between 10 and $20 \mathrm{~mm}$ [8]. In our cohort of patients, FNA would have been indicated in $85 \%$ of PTCs, $89 \%$ of MTCs, and only $56 \%$ of FTCs, if based solely on the EUTIRADS US criteria. This is a clear underdetection of FTC. For the three cancer types combined, 20 out of 118 cases, including 2 stage IV cancers, would have remained undiagnosed if the recommendations of the EU-TIRADS were followed.

The striking difference in the US-based FNA indication rate between FTC and non-FTC cancers was the consequence of the higher average EU-TIRADS scores in MTC (4.89) and PTC (4.80), compared to FTC (4.11). The substantially higher prevalence of suspicious US characteristics in non-FTC lesions is in accordance with the observations of others [13-16, 21, 22] (Table 4). Furthermore, similar to others, we found no significant difference between PTC and MTC as for the presence of suspicious US features [29, 30] and verified that the performance of EU-TIRADS in the diagnosis of MTC is as good as in PTC $[16,17]$.

Our findings confirm those of Castellana et al., hitherto the only study focusing on the performance of EU-TIRADS in the diagnosis of FTC [23]. However, while they demonstrated a $6.7 \%$ EU-TIRADS failure rate in diagnosing FTCs, it is as high as $20.0 \%$ in our study. The explanation lies in the way patients are selected for FNA; in the Castellana 

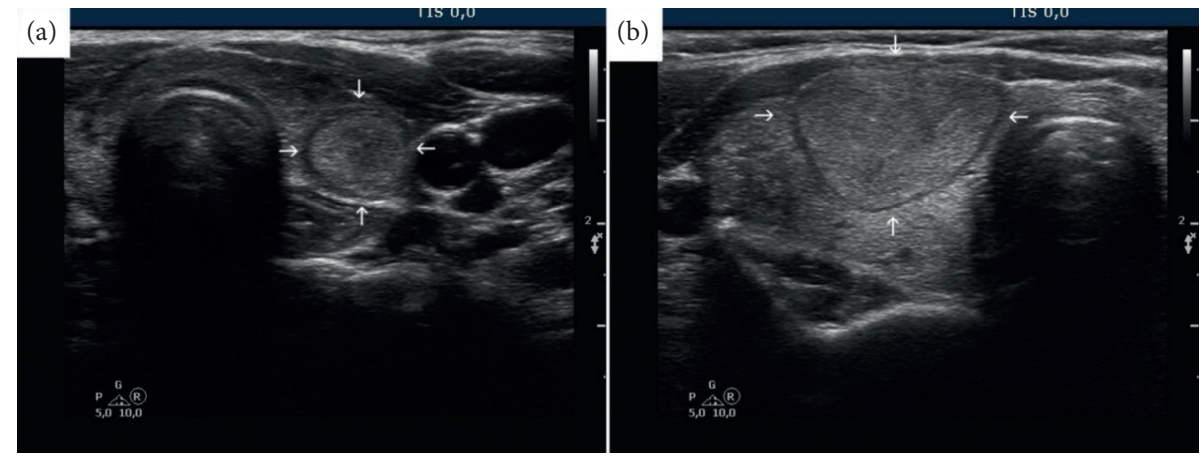

FIgURE 2: The importance of timely diagnosis of follicular thyroid cancer. (a) An EU-TIRADS score 3 nodule (arrows) with a maximum diameter of $12 \mathrm{~mm}$. According to EU-TIRADS, FNA is not indicated, and the diagnosis would have been missed. Final histology was minimally invasive follicular cancer restricted to the thyroid. (b) A $28 \mathrm{~mm}$ follicular cancer (arrows) metastasizing to the lungs. The patient was first examined in another hospital 12 years earlier. At that time, the diameter of the nodule was 14 mm, and FNA was not performed because of the absence of suspicious ultrasound characteristics.

TABLE 4: The occurrence of individual suspicious ultrasound characteristics in three subtypes of thyroid cancer. For comparison, previously published data are given ([11], [14-17], [22], [33], [39-56]).

\begin{tabular}{|c|c|c|c|c|c|c|}
\hline & \multicolumn{2}{|c|}{ Follicular cancer } & \multicolumn{2}{|c|}{ Medullary cancer } & \multicolumn{2}{|c|}{ Papillary cancer } \\
\hline & Mean \pm SD & Median (range) & Mean \pm SD & Median (range) & Mean \pm SD & Median (range) \\
\hline \multicolumn{7}{|c|}{ Marked hypoechogenicity } \\
\hline Present study & $22.2 \pm 19.4$ & & $44.4 \pm 27.8$ & & $25.0 \pm 43.5$ & \\
\hline Literature data & $5.2 \pm 15.3$ & $3.6(2.5-10.9)$ & $29.3 \pm 11.1$ & $32.7(19.6-52.4)$ & $38.5 \pm 24.6$ & $32.7(17.1-84-9)$ \\
\hline \multicolumn{7}{|l|}{ Microcalcifications } \\
\hline Present study & $44.4 \pm 27.8$ & & $44.4 \pm 27.8$ & & $65.0 \pm 47.9$ & \\
\hline Literature data & $16.2 \pm 22.1$ & $7.7(0-61.5)$ & $37.0 \pm 8.8$ & $37.5(16.7-47.2)$ & $49.5 \pm 25.0$ & $50.9(17.8-89.1)$ \\
\hline \multicolumn{7}{|l|}{ Irregular shape } \\
\hline Present study & $11.1 \pm 11.1$ & & $33.3 \pm 50.0$ & & $32.0 \pm 22.0$ & \\
\hline Literature data & $17.0 \pm 17.5$ & $14.1(0-44.4)$ & $27.4 \pm 19.7$ & $36.4(2.9-63.1)$ & $40.8 \pm 25.0$ & $36.4(9.6-74.0)$ \\
\hline \multicolumn{7}{|l|}{ Irregular borders } \\
\hline Present study & $33.3 \pm 50.0$ & & $55.6 \pm 52.7$ & & $46.0 \pm 50.0$ & \\
\hline Literature data & $23.3 \pm 19.4$ & $22.0(0-60.9)$ & $37.9 \pm 22.4$ & $45.2(0-63.6)$ & $48.2 \pm 28.9$ & $40.4(22.3-92.9)$ \\
\hline
\end{tabular}

All values are given in $\%$.

et al.' study [23], patients were referred to FNA (and thus surgery) if the US suspicion criteria were fulfilled, i.e., some FTCs have been overlooked due to lack of suspicious signs. The difference in mean tumor diameter of FTCs $(33 \mathrm{~mm}$ vs. $27 \mathrm{~mm}$ in their study and our study, respectively) is in line with this explanation. The larger the proportion of nodules $>2 \mathrm{~cm}$ in the study population, the lower the rate of failures of EU-TIRADS, because the EU-TIRADS scoring system calls for FNA in $<2 \mathrm{~cm}$ nodules only if suspicious signs are present. In our study, all nodules larger than $1 \mathrm{~cm}$ were sampled, thereby, avoiding selection bias.

Two conflicting views exist regarding the capacity of TIRADS in recognizing FTCs. The guideline of the American Thyroid Association considers it acceptable not to recognize FTCs smaller than $20 \mathrm{~mm}$ in their largest diameter because distant metastases occur rarely in such lesions [7]. The main argument in support of this view emphasizes the sparing of FNAs in benign lesions, a fact which has been convincingly shown $[3,11]$ but is beyond the scope of the current study. The ATA view is further supported by the lower incidence of FTC in areas of long ago achieved iodine sufficiency, such as the United States. The other view states that one has to exert every effort to recognize FTCs well before they reach $20 \mathrm{~mm}$ in diameter, because once the nodule becomes larger, distant metastases may evolve [31]. Furthermore, in Europe, FTC incidence remains around $10 \%$ of all thyroid cancers [32].

Compared to PTCs, FTCs are more likely to be iso or hyperechoic, noncalcified, round shaped, and halo encompassed with regular margins [33]. Conceivably, US risk stratification is fundamentally inadequate in identifying nodules that could be FTCs. One should be aware that while chasing PTCs, we are, to some extent, neglecting a more aggressive type of thyroid cancer [24, 27]. Furthermore, this eliminates the fundamental problem that FTCs can only be distinguished from follicular adenomas by histology. Considering the $1: 16$ to $1: 5$ ratio of FTC to follicular adenoma $[34,35]$, a large number of unnecessary FNAs could be spared if one were less committed to recognize FTC than PTC. The reliability of the current approaches in detecting FTCs should still be improved [27], either by modifying patterns and cutoffs for FNA or by 
TABLE 5: EU-TIRADS score-based indication of FNA related to tumor stage in the $10-20 \mathrm{~mm}$ size category.

\begin{tabular}{|c|c|c|c|c|c|c|c|}
\hline \multirow{2}{*}{ Cancer type } & \multirow{2}{*}{$n$} & \multicolumn{2}{|c|}{ TNM status } & \multicolumn{4}{|c|}{ Pathological staging } \\
\hline & & $\mathrm{T} 1$ & $\mathrm{~T} 2-\mathrm{T} 4$ & Stage I & Stage II & Stage III & Stage IV \\
\hline \multicolumn{8}{|l|}{ Papillary $(n=100)$} \\
\hline FNA indicated & 85 & 68 & 17 & 76 & 7 & 1 & 1 \\
\hline FNA not indicated & 15 & 12 & 3 & 12 & 2 & 0 & 1 \\
\hline \multicolumn{8}{|l|}{ Follicular $(n=9)$} \\
\hline FNA indicated & 5 & 5 & 0 & 5 & 0 & 0 & 0 \\
\hline FNA not indicated & 4 & 3 & 1 & 3 & 0 & 0 & 1 \\
\hline \multicolumn{8}{|l|}{ Medullary $(n=9)$} \\
\hline FNA indicated & 8 & 5 & 34 & 0 & 4 & 0 & \\
\hline FNA not indicated & 1 & 1 & 0 & 1 & 0 & 0 & 0 \\
\hline \multicolumn{8}{|l|}{ All $(n=118)$} \\
\hline FNA indicated & 98 & 75 & 23 & 73 & 8 & 1 & 16 \\
\hline FNA not indicated & 20 & 16 & 4 & 16 & 2 & 0 & 2 \\
\hline
\end{tabular}

EU-TIRADS, Thyroid Imaging Reporting and Data System of the European Thyroid Association [8].

integrating US with other technologies. Once selected for FNA, molecular testing and nuclear techniques [36] are future candidates for discriminating between follicular adenomas and follicular cancers.

As a main strength of the present study, we have tested the diagnostic sensitivity of an EU-TIRADS system in a cohort selected for FNA and surgery based on the preTIRADS approach, rather than the current focus on limiting number of FNAs. The true sensitivity of a method, in this case, TIRADS, can be tested only in such a nonrestricted cohort of patients. Most, if not all, recently published studies have estimated the diagnostic performance of TIRADS in cohorts selected for FNA and surgery based on the same principles on which the tested TIRADS method is based $[3,10,11,14,37,38]$. This implies that nodules which failed to show the required features of high suspicion escaped FNA and surgery and were therefore not diagnosed as malignant. This selection bias has prevented recognition of the low sensitivity of EU-TIRADS in detecting FTCs in the $10-20 \mathrm{~mm}$ range.

Our study design focused exclusively on the sensitivity, not the specificity, of EU-TIRADS. We acknowledge the merits of EU-TIRADS in the reduction of superfluous FNAs. This unquestionable benefit could have been investigated in patients operated on for benign lesions. However, in the present study, in almost all such patients, the dominant nodule was larger than $2 \mathrm{~cm}$, where TIRADS, independently of the score, suggests FNA.

The limitations of our study are its retrospective nature and the limited number of thyroid cancers in the relevant size range. Inherent inaccuracy of the cytology evaluation may have distorted the final results. Furthermore, this has been a single center study with all of the drawbacks of such observations, including limitations in generalizability. This limitation is even more important, in that all examinations were performed by the same investigator. Thus, our findings are calling for confirmation.

In conclusion, when evaluating the performance of EUTIRADS, analyses should focus preferentially on lesions in the size range where the US characteristics have a real impact on the indication for FNA, the $10-20 \mathrm{~mm}$ range. In this range, EU-TIRADS identified the majority of patients to be sampled for cytology in PTCs and MTCs, but indicated FNA only in half of the FTCs. TIRADS-based US criteria favor PTC and MTC characteristics over that of FTC. The diagnostic performance of TIRADS cannot be established in cohorts of patients in which the selection for FNA and surgery is based on suspicion criteria in which the TIRADS is based on. Such an approach underestimates the false-negative FTC rate of TIRADS-based decisions. Prospective studies to clarify the exact proportion of FTCs missed are warranted.

\section{Data Availability}

The data used to support the findings of this study are included within the article.

\section{Additional Points}

EU-TIRADS does not recognize half of the follicular cancers in the $10-20 \mathrm{~mm}$ range. Virtually, all studies in this field share a selection bias: the sensitivity of EU-TIRADS is tested in cohorts selected for cytology/surgery based on EUTIRADS ultrasound suspicion criteria.

\section{Ethical Approval}

The study complies with internationally accepted standards for research practice and reporting. Ethical approval number: 1-04.09.2020, Research Ethics Committee of Bugat Hospital, Gyöngyös, Hungary.

\section{Disclosure}

NKFIH has had no influence on the design, interpretation, or decision to publish this manuscript.

\section{Conflicts of Interest}

The authors declare that they have no conflicts of interest. 


\section{Authors' Contributions}

T. Solymosi designed the study and collected data and first and last versions of the manuscript. L. Hegedüs designed the study, prepared the manuscript, and approved the final manuscript. M. Bodor prepared first and last versions of the manuscript. E.V. Nagy designed the study and approved the final manuscript.

\section{Acknowledgments}

This work was supported by the Hungarian National Research, Development, and Innovation Office, NKFIH (K116419).

\section{Supplementary Materials}

Supplementary Figure 1. The occurrence of individual suspicious ultrasound characteristics in three subtypes of thyroid cancer. For comparison, previously published data are shown (refs [11], [14-17], [22], [33], [39-56]). FTC follicular thyroid cancer, MTC - medullary thyroid cancer, PTC - papillary thyroid cancer. All values are \%. (Supplementary Materials)

\section{References}

[1] L. Hegedüs, "The thyroid nodule," New England Journal of Medicine, vol. 351, no. 17, pp. 1764-1771, 2004.

[2] H. Gharib, E. Papini, R. Valcavi et al., "AACE/AME task force on thyroid nodules. American association of clinical Endocrinologists and associazione medici endocrinologi medical guidelines for clinical practice for the diagnosis and management of thyroid nodules," Endocrine Practice, vol. 12, no. 1, pp. 63-102, 2006.

[3] T. Xu, Y. Wu, R.-X. Wu et al., "Validation and comparison of three newly-released thyroid imaging reporting and data systems for cancer risk determination," Endocrine, vol. 64, no. 2, pp. 299-307, 2019.

[4] E. Horvath, S. Majlis, R. Rossi et al., "An ultrasonogram reporting system for thyroid nodules stratifying cancer risk for clinical management," The Journal of Clinical Endocrinology \& Metabolism, vol. 94, no. 5, pp. 1748-1751, 2009.

[5] H. Gharib, E. Papini, J. R. Garber et al., "American association of clinical endocrinologists, American college of endocrinology, and associazione medici endocrinologi medical guidelines for clinical practice for the diagnosis and management of thyroid nodules-2016 update," Endocrine Practice: Official Journal of the American College of Endocrinology and the American Association of Clinical Endocrinologists, vol. 22, no. 5, pp. 622-639, 2016 May.

[6] F. N. Tessler, W. D. Middleton, E. G. Grant et al., "ACR thyroid imaging, reporting and data system (TI-RADS): white paper of the ACR TI-RADS committee," Journal of the American College of Radiology, vol. 14, no. 5, pp. 587-595, 2017.

[7] B. R. Haugen, E. K. Alexander, K. C. Bible et al., “American thyroid association management guidelines for adult patients with thyroid nodules and differentiated thyroid cancer: the American thyroid association guidelines task force on thyroid nodules and differentiated thyroid cancer," Thyroid, vol. 26, no. 1, pp. 1-133, 2015.
[8] G. Russ, S. J. Bonnema, M. F. Erdogan, C. Durante, R. Ngu, and L. Leenhardt, "European thyroid association guidelines for ultrasound malignancy risk stratification of thyroid nodules in adults: the EU-TIRADS," European Thyroid Journal, vol. 6, no. 5, pp. 225-237, 2017 Sep.

[9] J. H. Shin, J. H. Baek, J. Chung et al., "Ultrasonography diagnosis and imaging-based management of thyroid nodules: revised Korean Society of Thyroid Radiology consensus statement and recommendations," Korean Journal of Radiology, vol. 17, no. 3, pp. 370-395, 2016.

[10] A. L. Tang, M. Falciglia, H. Yang, J. R. Mark, and D. L. Steward, "Validation of American thyroid association ultrasound risk assessment of thyroid nodules selected for ultrasound fine-needle aspiration," Thyroid, vol. 27, no. 8, pp. 1077-1082, 2017.

[11] P. Trimboli, R. Ngu, B. Royer et al., "A multicentre validation study for the EU-TIRADS using histological diagnosis as a gold standard," Clinical Endocrinology, vol. 91, no. 2, pp. 340-347, 2019.

[12] G. Grani, L. Lamartina, V. Ascoli et al., "Reducing the number of unnecessary thyroid biopsies while improving diagnostic accuracy: toward the "right" TIRADS," The Journal of Clinical Endocrinology \& Metabolism, vol. 104, no. 1, pp. 95-102, 2019.

[13] D. G. Na, J. H. Baek, J. Y. Sung et al., "Thyroid imaging reporting and data system risk stratification of thyroid nodules: categorization based on solidity and echogenicity," Thyroid, vol. 26, no. 4, pp. 562-572, 2016.

[14] J. H. Yoon, K. Han, E.-K. Kim, H. J. Moon, and J. Y. Kwak, "Diagnosis and management of small thyroid nodules: a comparative study with six guidelines for thyroid nodules," Radiology, vol. 283, no. 2, pp. 560-569, 2017.

[15] E. J. Jeon, Y. J. Jeong, S. H. Park, C. H. Cho, H. S. Shon, and E. D. Jung, "Ultrasonographic characteristics of the follicular variant papillary thyroid cancer according to the tumor size," Journal of Korean Medical Science, vol. 31, no. 3, pp. 397-402, 2016.

[16] J. Zhu, X. Li, X. Wei et al., "The application value of modified thyroid imaging report and data system in diagnosing medullary thyroid carcinoma," Cancer Medicine, vol. 8, no. 7, pp. 3389-3400, 2019.

[17] G. Yun, Y. K. Kim, S. I. Choi, and J.-H. Kim, "Medullary thyroid carcinoma: application of thyroid imaging reporting and data system (TI-RADS) classification," Endocrine, vol. 61, no. 2, pp. 285-292, 2018.

[18] S. Y. Hahn, J. H. Shin, Y. L. Oh, and K. W. Park, "Ultrasonographic characteristics of medullary thyroid carcinoma according to nodule size: application of the Korean thyroid imaging reporting and data system and American thyroid association guidelines," Acta Radiologica, vol. 62, no. 4, pp. 474-482, 2020.

[19] P. Valderrabano, D. L. Klippenstein, J. B. Tourtelot et al., "New American thyroid association sonographic patterns for thyroid nodules perform well in medullary thyroid carcinoma: institutional experience, systematic review, and metaanalysis," Thyroid, vol. 26, no. 8, pp. 1093-1100, 2016.

[20] J. Li, H. Li, Y. Yang, X. Zhang, and L. Qian, “The KWAK TIRADS and 2015 ATA guidelines for medullary thyroid carcinoma: combined with cell block-assisted ultrasound-guided thyroid fine-needle aspiration," Clinical Endocrinology, vol. 92, no. 5, pp. 450-460, 2020.

[21] C.-L. Chng, T. R. Kurzawinski, and T. Beale, "Value of sonographic features in predicting malignancy in thyroid nodules diagnosed as follicular neoplasm on cytology," Clinical Endocrinology, vol. 83, no. 5, pp. 711-716, 2015.

[22] J. W. Park, D. W. Kim, D. Kim, J. W. Baek, Y. J. Lee, and H. J. Baek, "Korean Thyroid Imaging Reporting and Data 
System features of follicular thyroid adenoma and carcinoma: a single-center study," Ultrasonography, vol. 36, no. 4, pp. 349-354, 2017.

[23] M. Castellana, A. Piccardo, C. Virili et al., "Can ultrasound systems for risk stratification of thyroid nodules identify follicular carcinoma?" Cancer Cytopathology, vol. 128, no. 4, pp. 250-259, 2020.

[24] P. Trimboli and C. Durante, "Ultrasound risk stratification systems for thyroid nodule: between lights and shadows, we are moving towards a new era," Endocrine, vol. 69, no. 1, pp. 1-4, 2020.

[25] G. Grani, L. Lamartina, C. Durante, S. Filetti, and D. S. Cooper, "Follicular thyroid cancer and Hürthle cell carcinoma: challenges in diagnosis, treatment, and clinical management," The Lancet Diabetes \& Endocrinology, vol. 6, no. 6, pp. 500-514, 2018.

[26] M. E. Cabanillas, D. G. McFadden, and C. Durante, "Thyroid cancer," The Lancet, vol. 388, no. 10061, pp. 2783-2795, 2016.

[27] P. Trimboli, M. Castellana, A. Piccardo et al., "The ultrasound risk stratification systems for thyroid nodule have been evaluated against papillary carcinoma," A Meta-Analysis. Reviews in Endocrine \& Metabolic Disorders, vol. 22, no. 2, pp. 453-460, 2020.

[28] M. Tuttle and L. F. Morris, "Thyroid-differentiated and anaplastic carcinoma," in AJCC Cancer Staging Manual, M. B. Amin, S. B. Edge, and Greene, Eds., Springer International Publishing, New York, NY, USA, 8th edition, 2017.

[29] N. Choi, W.-J. Moon, J. H. Lee, J. H. Baek, D. W. Kim, and S.-W. Park, "Ultrasonographic findings of medullary thyroid cancer: differences according to tumor size and correlation with fine needle aspiration results," Acta Radiologica, vol. 52, no. 3, pp. 312-316, 2011.

[30] K. Woliński, M. Rewaj-Łosyk, and M. Ruchała, "Sonographic features of medullary thyroid carcinomas--a systematic review and meta-analysis," Endokrynologia Polska, vol. 65, no. 4, pp. 314-318, 2014.

[31] A. Machens, H.-J. Holzhausen, and H. Dralle, "The prognostic value of primary tumor size in papillary and follicular thyroid carcinoma," Cancer, vol. 103, no. 11, pp. 2269-2273, 2005.

[32] L. Dal Maso, A. Tavilla, F. Pacini et al., "Survival of 86,690 patients with thyroid cancer: a population-based study in 29 European countries from EUROCARE-5," European Journal of Cancer, vol. 77, pp. 140-152, 2017.

[33] S.-k. Jeh, S. L. Jung, B. S. Kim, and Y. S. Lee, "Evaluating the degree of conformity of papillary carcinoma and follicular carcinoma to the reported ultrasonographic findings of malignant thyroid tumor," Korean Journal of Radiology, vol. 8, no. 3, pp. 192-197, 2007.

[34] C. R. McHenry and R. Phitayakorn, "Follicular adenoma and carcinoma of the thyroid gland," The Oncologist, vol. 16, no. 5, pp. 585-593, 2011.

[35] T. Solymosi, G. L. Tóth, I. Gál, C. Sajgó, and I. Szabolcs, "Influence of iodine intake on the diagnostic power of fineneedle aspiration cytology of the thyroid gland," Thyroid, vol. 12, no. 8, pp. 719-723, 2002.

[36] A. Campennì, L. Giovanella, M. Siracusa et al., "(99m) TcMethoxy-Isobutyl-Isonitrile scintigraphy is a useful tool for assessing the risk of malignancy in thyroid nodules with indeterminate fine-needle cytology," Thyroid, vol. 26, no. 8, pp. 1101-1109, 2016.

[37] D. Słowińska-Klencka, K. Wysocka-Konieczna, E. WoźniakOseła et al., "Thyroid nodules with Hürthle cells: the malignancy risk in relation to the FNA outcome category,"
Journal of Endocrinological Investigation, vol. 42, no. 11, pp. 1319-1327, 2019.

[38] D. Słowińska-Klencka, K. Wysocka-Konieczna, M. Klencki, and B. Popowicz, "Diagnostic value of six thyroid imaging reporting and data systems (TIRADS) in cytologically equivocal thyroid nodules," Journal of Clinical Medicine, vol. 9, no. 7, p. 2281, 2020.

[39] S. H. Lee, J. S. Baek, J. Y. Lee et al., "Predictive factors of malignancy in thyroid nodules with a cytological diagnosis of follicular neoplasm," Endocrine Pathology, vol. 24, no. 4, pp. 177-183, 2013.

[40] H. S. Seo, D. H. Lee, S. H. Park, H. S. Min, and D. G. Na, "Thyroid follicular neoplasms: can sonography distinguish between adenomas and carcinomas?" Journal of Clinical Ultrasound, vol. 37, no. 9, pp. 493-500, 2009.

[41] X. Lai, Y. Jiang, B. Zhang et al., "Preoperative sonographic features of follicular thyroid carcinoma predict biological behavior," Medicine, vol. 97, no. 41, Article ID e12814, 2018.

[42] J.-Z. Zhang and B. Hu, "Sonographic features of thyroid follicular carcinoma in comparison with thyroid follicular adenoma," Journal of Ultrasound in Medicine, vol. 33, no. 2, pp. 221-227, 2014.

[43] T.-C. Kuo, M.-H. Wu, K.-Y. Chen, M.-S. Hsieh, A. Chen, and C.-N. Chen, "Ultrasonographic features for differentiating follicular thyroid carcinoma and follicular adenoma," Asian Journal of Surgery, vol. 43, no. 1, pp. 339-346, 2020.

[44] N. E. Gulcelik, M. A. Gulcelik, and B. Kuru, "Risk of malignancy in patients with follicular neoplasm," Archives of Otolaryngology-Head and Neck Surgery, vol. 134, no. 12, pp. 1312-1315, 2008.

[45] Y. J. Choi, J. S. Yun, and D. H. Kim, "Clinical and ultrasound features of cytology diagnosed follicular neoplasm," Endocrine Journal, vol. 56, no. 3, pp. 383-389, 2009.

[46] Y. S. Song, J.-H. Kim, D. G. Na et al., "Ultrasonographic differentiation between nodular hyperplasia and neoplastic follicular-patterned lesions of the thyroid gland," Ultrasound in Medicine and Biology, vol. 42, no. 8, pp. 1816-1824, 2016.

[47] S. Lee, J. H. Shin, B.-K. Han, and E. Y. Ko, "Medullary thyroid carcinoma: comparison with papillary thyroid carcinoma and application of current sonographic criteria," American Journal of Roentgenology, vol. 194, no. 4, pp. 1090-1094, 2010.

[48] S.-H. Kim, B.-S. Kim, S.-L. Jung et al., "Ultrasonographic findings of medullary thyroid carcinoma: a comparison with papillary thyroid carcinoma," Korean Journal of Radiology, vol. 10, no. 2, pp. 101-105, 2009.

[49] S. Cai, H. Liu, W. B. Li et al., "Ultrasonographic features of medullary thyroid carcinoma and their diagnostic values," Chinese Medical Journal, vol. 123, no. 21, pp. 3074-3078, 2010.

[50] B. Saller, L. Moeller, R. Görges, O. E. Janssen, and K. Mann, "Role of conventional ultrasound and color Doppler sonography in the diagnosis of medullary thyroid carcinoma," Experimental and Clinical Endocrinology \& Diabetes: Official Journal, German Society of Endocrinology [and] German Diabetes Association, vol. 110, no. 8, pp. 403-407, 2002.

[51] K. E. Cho, H. M. Gweon, A. Y. Park et al., "Ultrasonographic features of medullary thyroid carcinoma: do they correlate with pre and postoperative calcitonin levels?" Asian Pacific Journal of Cancer Prevention: Asian Pacific Journal of Cancer Prevention, vol. 17, no. 7, pp. 3357-3362, 2016.

[52] J. H. Yoon, E.-K. Kim, S. W. Hong, J. Y. Kwak, and M. J. Kim, "Sonographic features of the follicular variant of papillary thyroid carcinoma," Journal of Ultrasound in Medicine, vol. 27, no. 10, pp. 1431-1437, 2008. 
[53] S. Y. Hahn, B.-K. Han, E. Y. Ko, J. H. Shin, and E. S. Ko, "Ultrasound findings of papillary thyroid carcinoma originating in the isthmus: comparison with lobe-originating papillary thyroid carcinoma," American Journal of Roentgenology, vol. 203, no. 3, pp. 637-642, 2014.

[54] A. Salmaslioğlu, Y. Erbil, C. Dural et al., "Predictive value of sonographic features in preoperative evaluation of malignant thyroid nodules in a multinodular goiter," World Journal of Surgery, vol. 32, no. 9, pp. 1948-1954, 2008.

[55] C. Cappelli, M. Castellano, I. Pirola et al., "Thyroid nodule shape suggests malignancy," European Journal of Endocrinology, vol. 155, no. 1, pp. 27-31, 2006.

[56] A. Sharma, H. Gabriel, A. A. Nemcek, R. Nayar, H. Du, and P. Nikolaidis, "Subcentimeter thyroid nodules: utility of sonographic characterization and ultrasound-guided needle biopsy," AJR. American journal of roentgenology, vol. 197, no. 6, pp. W1123-W1128, 2011. 